\title{
Asociacionismo migrante latinoamericano y codesarrollo. Ámbitos de participación política transnacional
}

\author{
Almudena Cortés Maisonave \\ Universidad Complutense de Madrid. Departamento de Antropología Social y Psicología \\ Social \\ almudena.cortes@cps.ucm.es
}

\section{Anna Sanmartín Ortí}

Centro Reina Sofía sobre Adolescencia y Juventud-FAD

asanmartin@fad.es

\section{Resumen}

El texto analiza cómo las trayectorias y las características de las tramas asociativas migrantes condicionan el impulso y la puesta en práctica del codesarrollo en la ciudad de Madrid, además de cómo la manera en que ha sido impulsado el codesarrollo ha impactado a su vez en el discurso, la orientación y el proceso de transnacionalización de las asociaciones de migrantes. El análisis de material de campo (revisión de webs y documentos de las asociaciones, entrevistas a representantes asociativos y asistencia a reuniones y a eventos de las organizaciones), muestra que el codesarrollo ha sido entendido como una ventana de oportunidad por las asociaciones, para incidir políticamente de manera transnacional, reforzar su liderazgo y participar en los proyectos políticos de los contextos de origen. El trabajo contribuye a estudiar un tema muy poco trabajado para el caso español y la población latinoamericana. La principal innovación de este texto consiste en vincular el enfoque de las estructuras de oportunidad política con la perspectiva transnacional para conocer con más profundidad el alcance de la participación política transnacional de las asociaciones de migrantes.

Palabras clave: migración latinoamericana; asociacionismo; participación política; transnacionalismo; prácticas políticas transnacionales; cooperación internacional 


\begin{abstract}
Latin American migrant associations and co-development: Areas of transnational political participation
\end{abstract}

The article analyzes how the trajectories and characteristics of migrant associations determine the promotion and implementation of co-development in the city of Madrid, Spain, and how the way co-development has been promoted has impacted on the discourse, orientation and transnationalization process of migrant associations. Through the analysis of field material (review of association websites and documents, interviews with associative representatives and attendance at meetings and events of the organizations), the text shows how co-development has been understood by associations as a window of opportunity to influence politics in a transnational way, strengthen their leadership and participate in political projects in the contexts of origin. The work contributes to the study of a scarcely analyzed topic for the Spanish case and the Latin American population. The main innovation of the study is the link between a political opportunity structures focus and a transnational perspective to explore in greater depth the scope of transnational political participation of migrant associations.

Keywords: Latin American migration; associationalism; political participation; transnationalism; transnational political practices; international cooperation

\title{
Sumario
}

1. Introducción: participación política transnacional, asociacionismo y codesarrollo

2. La participación política transnacional y el asociacionismo migrante

3. Análisis de casos: la práctica del codesarrollo en la ciudad de Madrid
4. Administraciones locales, promoción del codesarrollo y asociaciones de migrantes

5. Conclusiones

Referencias bibliográficas

\section{Introducción: participación política transnacional, asociacionismo y codesarrollo}

Este texto analiza la participación política de los migrantes a través de sus asociaciones y de su implicación en proyectos de cooperación para el desarrollo - denominados proyectos de codesarrollo —, en unos años en los que España apostó claramente por su impulso y su implementación ${ }^{1}$. Entenderemos por codesarrollo un tipo de conexión institucional entre migración y desarrollo impulsado, en primer lugar, desde Francia y, posteriormente, desde España con los países de procedencia de los grupos de migrantes más numerosos. Nos encontramos ante una categoría claramente europea ${ }^{2}$, orientada a intervenir

1. El Programa GRECO (2002-2004) y el Plan Director de la Cooperación Española 20052008 recogían el concepto y las prácticas de codesarrollo. El término desaparece de los planes gubernamentales a partir del Plan Director 2013-2016, donde apenas se alude ya a la cuestión migratoria.

2. Sin ánimo de ser exhaustivas, entre la bibliografía especializada para el caso español destacan las siguientes obras: El codesarrollo en España: Protagonistas, discursos y experiencias (2006), 
en la esfera internacional y nacional aprovechando la dimensión transnacional de las migraciones internacionales. Sin embargo, desde el comienzo de su implementación desde España, la participación de los migrantes a través de sus asociaciones fue un elemento clave y supuso una diversificación de los actores que participaban en los proyectos con financiación pública. De hecho, las asociaciones empezaron a disputar un espacio que tradicionalmente había estado ocupado por las ONG del desarrollo, que se presentaban como las que disponían de conocimiento experto frente a las primeras. El codesarrollo se fue abriendo paso como un conjunto de iniciativas y proyectos en los cuales participaba «una red ampliada de actores» (administraciones públicas de España y de los países de origen, asociaciones de migrantes, preasociaciones y grupos de familiares, organizaciones no gubernamentales de desarrollo, etc.) ubicados en varios lugares y que interactuaban de manera transnacional desde diferentes escalas de poder. Estos actores perseguían distintos intereses y empezaron a desarrollar sus actividades creando un nuevo ámbito de conexión y convergencia entre la sociedad civil y el Estado, sobre todo entre las administraciones locales y las asociaciones de migrantes. Es decir, podían encontrarse iniciativas de codesarrollo impulsadas y promovidas «desde arriba", desde las administraciones públicas, y otras prácticas implementadas «desde abajo», puestas en marcha por grupos de migrantes organizados que estaban vinculados de diferentes maneras a sus lugares de origen y que posteriormente consiguieron o no el apoyo de las administraciones públicas.

Sabemos, por las conclusiones obtenidas en trabajos anteriores, que el ámbito de lo local constituye el mejor espacio de incidencia desde el cual los migrantes se piensan como actores y sujetos políticos (Cortés y Sanmartín, 2009). Es su vinculación con sus localidades de origen (barrios, parroquias, cantones, provincias, regiones, etc.) lo que da sentido a su participación, ya que es aquí, en primer lugar, donde viven y residen los familiares de los migrantes. Pero, del mismo modo, los contextos locales donde viven los migrantes también pueden ser objeto de vinculación, al residir otros miembros de la familia, aquellos que han sido reagrupados o aquellos con los que se forman nuevas familias, lo que da lugar a familias transnacionales. Así, las asociaciones de migrantes dan respuestas diversas a estas formas de vinculación prestando más atención al contexto de partida, al de migración o a ambos. Una gran parte de las actividades políticas realizadas por los migrantes se relaciona con los proyectos que sus asociaciones llevan a cabo en su pueblo o en su región natal, lo que se plasma de una forma muy clara en los proyectos de codesarrollo impulsados desde España (Østergaard-Nielsen, 2009: 22; Sanmartín, 2010; Cortés, 2011).

de Giménez, Martínez, Fernández y Cortés; La construcción del codesarrollo (2008), de Fernández, Giménez y Puerto; Codesarrollo en los Andes: Contextos y actores para una acción transnacional (2009), de Cortés y Torres; El codesarrollo en España: Un análisis de la implicación de los migrantes (2010), de Anna Sanmartín, y Estados, Cooperación para el Desarrollo y Migraciones: El caso del codesarrollo entre Ecuador y España (2011), de Almudena Cortés. 
En este artículo prestamos una atención especial al modo en que España ha constituido y constituye un contexto específico dentro del marco europeo a partir del cual se han construido y reinventado las prácticas transnacionales de los migrantes a través del codesarrollo y de las asociaciones de migrantes. Este texto plantea que en España han ido surgiendo comunidades transnacionales de migrantes mientras el país iba convirtiéndose en un foco de atracción de la migración internacional, comunidades que han ido consolidándose y reconfigurándose con el tiempo paralelamente a las trayectorias de los propios grupos migrantes. Por ejemplo, los vínculos transnacionales familiares y de amistad son los que han permitido activar la movilidad dentro de la UE de población latinoamericana nacionalizada española que, en plena crisis, ha migrado a otros países que ofrecían oportunidades de trabajo (Reino Unido o Alemania) como estrategia para afrontar la crisis en España (Cortés et al. 2015; Mas Giralt, 2017; Ramos, 2017). Pero, además, no solo España se ha ido transformando en un espacio transnacional europeo, cruzado por prácticas diversas (políticas, económicas o culturales), sino que dichas prácticas han ido diversificándose y diferenciándose en función de las relaciones específicas de carácter económico, político, cultural, religioso y racial que España mantiene con los contextos de origen de las comunidades transnacionales. «De este modo, España es resignificada como un espacio social simbólico a partir de las prácticas transnacionales de los migrantes, y es desde este marco significativo desde el cual se impulsan acciones por parte de las asociaciones de migrantes con el fin de incidir en el desarrollo y transformar las condiciones de vida de los contextos de origen» (Cortés y Sanmartín, 2009: 193).

Por todo ello, en este texto nos preguntamos cómo las trayectorias y las características de las tramas asociativas migrantes condicionaron o no el impulso y la puesta en práctica del codesarrollo en la ciudad de Madrid, ilustrando estas actividades a partir de las trayectorias de las asociaciones latinoamericanas. Y, a su vez, cómo la manera en que el codesarrollo fue impulsado ha ejercido un enorme impacto en el discurso, en la orientación de trabajo y en el proceso de transnacionalización de las asociaciones de migrantes. El codesarrollo coloca en el centro de los proyectos la movilidad de recursos (remesas, formación, ideas de cambio y contactos) y sitúa a los migrantes como agentes clave aquí y allí.

En concreto, mostraremos cómo el codesarrollo fue entendido como una ventana de oportunidad por las asociaciones para influir en los contextos locales y nacionales de partida y aumentar su caudal de prestigio, reforzar su liderazgo y participar y formar parte de los proyectos políticos en los contextos de partida y de pertenencia transnacional. De esta manera contribuiremos a analizar un tema muy poco trabajado para el caso español y la población latinoamericana, aunque se ha empezado a estudiar de manera más reciente en comparación con la atención prestada a los países europeos centrales, con una trayectoria migratoria más dilatada. Así, con este trabajo esperamos contribuir a los debates de la agenda europea de investigación sobre participación política transnacional.

El artículo presenta datos de las tesis doctorales de ambas autoras, así como datos actualizados e inéditos del proyecto de investigación Asociacio- 
nismo migrante y codesarrollo vinculado a la ciudad de Madrid: Una perspectiva comparada y teórico-aplicada ${ }^{3}$, financiada por la II Convocatoria de Proyectos de Investigación de la Red Universitaria de Investigación sobre Cooperación para el Desarrollo en el periodo 2008-2009. Esto ha permitido ir más allá de un mero análisis descriptivo y sincrónico, así como poder seguir los cambios de las asociaciones a lo largo de un periodo de tiempo más largo, aplicando un análisis diacrónico. La metodología usada en dicho proyecto fue etnográfica y cualitativa, basada en estudios de caso y en historias asociativas como núcleo específico y privilegiado en la investigación. Las técnicas consistieron en el examen de fuentes secundarias (revisión de literatura y documentos de las propias asociaciones), la realización de entrevistas a informantes que fueron claves y la asistencia a distintos eventos y actividades de asociaciones en la ciudad de Madrid.

Se realizó una primera fase exploratoria de localización de organizaciones de inmigrantes - asociaciones y federaciones - vinculadas a las nacionalidades más representadas en España y en Madrid ${ }^{4}$, junto a REDCO (Red de Asociaciones de Inmigrantes y Codesarrollo), fundada en abril de 2007 y de evidente interés en el marco de la investigación. El criterio que guió el rastreo inicial buscaba discriminar posiciones e itinerarios diversos en el tejido asociativo, teniendo en cuenta los siguientes elementos de clasificación: implicación en iniciativas y proyectos de codesarrollo (en diferentes grados, intensidades y maneras); antigüedad; tamaño y escala (número de socios, organización y recursos); red de relaciones de la entidad; tipo de liderazgo; adscripción étnica y regional de origen; área geopolítica y cultural (América Andina, Caribe, Magreb, África Subsahariana y Europa del Este), y estructura y densidad de la comunidad transnacional.

De entre las organizaciones identificadas, en una segunda fase y para profundizar en los estudios de caso, se seleccionó una muestra de asociaciones cuyos itinerarios resultaban particularmente representativos de alguna de las características detectadas y se optó además por limitar la selección a asociaciones latinoamericanas, al ser las más representadas en el municipio de Madrid y las que contaban con una actividad más visible en el ámbito del codesarrollo.

Debido a que el codesarrollo ha constituido un ámbito transnacional de participación política, en la primera parte de este texto vamos a presentar la discusión teórica que sirvió de base a nuestro análisis, centrada en la participación

3. Proyecto dirigido por Carlos Giménez (UAM) y María Jesús Criado (UCM), que contó con Almudena Cortés, Anna Sanmartín y Claudia Lucía Sierra como equipo investigador.

4. Entre ellas, las latinoamericanas ACULCO y AESCO (Colombia); ACOBE (Bolivia); Rumiñahui, asociación de espindolenses residentes en Madrid (vinculadas ambas a Ecuador); ARI-Perú, Asociación Centro Cultural César Vallejo (Perú), y VOMADE (República Dominicana); las marroquíes REMCODE e IBN-Batuta; la Asociación de Inmigrantes Senegaleses en España (AISE); la Asociación de Malienses Comín de Sana; FEDROM (Federación de Asociaciones Rumanas en España), y AIBE-BALCAN (Asociación de Inmigrantes Búlgaros en España). De entre todas las nombradas, el proyecto y las citas que se recogen en este texto muestran los casos de las asociaciones latinoamericanas, las más representativas para dar cuenta del objeto de estudio. 
política transnacional, en el transnacionalismo político y en el asociacionismo migrante. Analizaremos el codesarrollo como una ventana de oportunidad de alcance transnacional para las asociaciones. En segundo lugar, presentamos el análisis del material de campo de los casos seleccionados (las asociaciones de migrantes latinoamericanos implicados en proyectos de codesarrollo), con el objetivo de mostrar la interacción entre las asociaciones, los proyectos de codesarrollo y la participación política transnacional. En tercer lugar, analizamos el papel de la Administración local en la promoción del codesarrollo. El último apartado se encuentra dedicado a las conclusiones finales.

\section{La participación política transnacional y el asociacionismo migrante}

El transnacionalismo evoca un conjunto de imágenes de un movimiento permanente de ida y vuelta en el que los migrantes viven, simultáneamente, en dos o más sociedades, enlazándose entre sí a través de comunidades «desterritorializadas» (Basch et al., 1994). De este modo, el transnacionalismo está conformado por procesos moldeados con múltiples facetas y ubicaciones que incluyen prácticas económicas, socioculturales y políticas, así como discursos que trascienden los confines de la jurisdicción territorialmente circunscrita del Estado nación y son parte inherente de la vida cotidiana de los involucrados (Guarnizo et al., 2003). Las relaciones transnacionales se consideran parte de la vida diaria de las personas cuando su ausencia impide o interrumpe drásticamente el patrón de sus actividades habituales, ya sean sociales, económicas, culturales o políticas. Estas relaciones establecidas por los protagonistas sociales, individuales o colectivos implican el intercambio de un torbellino de recursos tangibles e intangibles que incluye a personas (que emigran, que vuelven a emigrar, que visitan su hogar con regularidad); a recursos monetarios (inversiones comerciales, remesas familiares, ayuda humanitaria); recursos no monetarios (ideas y símbolos culturales), y a apoyo político y oposición. Siguiendo el esquema propuesto por Dore et al. (2003: 160), diremos que las prácticas transnacionales de los migrantes pueden ser clasificadas en cuatro categorías (económicas, políticas, cívico-sociales u organizativas y culturales). En este trabajo vamos a centrarnos en las prácticas políticas transnacionales. Siguiendo la clasificación de Sørensen et al. (2002: 12), entendemos por prácticas políticas transnacionales aquellas emprendidas por los migrantes a través de las organizaciones sociales y culturales creadas en torno a la migración y que se basan en la participación en grupos formales e informales de migrantes (asociaciones de diversa índole). Entre otras cosas, la participación en asociaciones o grupos informales permite sortear las dificultades para la ciudadanía real y efectiva, al no vincularse de forma directa con el territorio de llegada (Goldring, 1998) y poner en práctica estructuras paralelas de poder (Smith, 1998). De este modo, mediante sus acciones, los migrantes están dotando de otro significado el papel que venía desempeñando el territorio, de tal modo que los sujetos transnacionales resignifican el sentido de territorialidad tal y como lo veníamos entendiendo hasta la fecha. 
Las asociaciones de migrantes se han implicado en el desarrollo desde una perspectiva transnacional y local a través del codesarrollo mediante la movilización de redes verticales y horizontales, tanto en el país de origen como en el de destino, lo que también ha permitido recoger inicialmente el interés de España y de los estados de origen en apoyar estas actividades (Lacomba, 2015). Los grupos y las asociaciones de migrantes cumplen varias funciones, como la asistencia en el proceso migratorio, la adaptación y la incorporación de los migrantes, la representación de la comunidad inmigrante y, finalmente, la vinculación de las comunidades con sus lugares de origen (Cordero-Guzmán, 2005: 901-907). De igual modo, estas asociaciones envían dinero para financiar proyectos en el origen y también pueden implicarse en actividades culturales, educativas, deportivas y sociales en el lugar de destino (Goldring, 2002: 62). Pueden revestir la forma de comités del pueblo, entendidos como grupos cívicos transnacionales autónomos que suelen estar formados por equipos heterogéneos de migrantes de la misma procedencia geográfica, cuya tarea consiste en organizar actividades sociales y culturales en el lugar de llegada con el fin de recaudar fondos para proyectos de mejoramiento en el lugar de origen, como la pavimentación de carreteras, las instalaciones de energía eléctrica, etc. (Landolt et al., 2003: 146-7). Junto a esto, se encuentran las acciones a realizar en el lugar de destino y cuyos objetivos consisten en realizar actividades como talleres para jóvenes inmigrantes, mediación intercultural y apoyo escolar, etc.; cabildear a los políticos locales sobre la situación de los migrantes en materia de educación, bajos ingresos, política migratoria, u orientar el cabildeo del gobierno de origen en el gobierno del país receptor sobre asuntos migratorios (Landolt et al., 2003: 148; GRDR, 2005). Estas asociaciones se han ido configurando en magníficas plataformas de impulso de acciones transnacionales con un claro sentido de incidencia política para mejorar, en primer lugar, la situación de los migrantes y sus familiares, tanto en origen como en destino. Pero, además, para dar salida a reivindicaciones históricas que determinados grupos ya venían realizando antes de migrar.

Lo que parece claro es que el interés político transnacional de los migrantes no desaparece con el tiempo ni es reemplazado por las preocupaciones de la situación política en el país de residencia. Del mismo modo, no todos los migrantes participan en actividades políticas, y si participan no lo hacen con la misma intensidad ni en el mismo grado. Así, es habitual pensar que los migrantes empiezan a realizar actividades políticas una vez que llegan a Europa, o a las ciudades donde residen, con lo que se niega o se oculta que los migrantes ya participaban en actividades políticas y pertenecían a organizaciones de distinto tipo antes de migrar (partidos políticos, sindicatos, asociaciones de vecinos, cooperativas de ahorro y crédito, etc.). Del mismo modo, la participación política transnacional está influida por la manera y por el grado en que la política de la patria natal importa a los migrantes y por las políticas dirigidas a cortejar a los migrantes en el exterior, al mismo tiempo que tiene que ver con el grado y con el tipo de relación que los migrantes establecen con las instituciones políticas del país receptor. Además, las organizaciones inter- 
nacionales y las ONG desempeñan un papel clave al entrelazarse con las redes políticas transnacionales de los migrantes. Este aspecto ha sido especialmente significativo en el caso de los proyectos de codesarrollo, ya que las ONG han desempeñado un papel muy relevante a la hora de apoyar y/o de competir con las asociaciones de migrantes, quienes reclamaban un espacio legítimo para encargarse de las acciones de codesarrollo.

Siguiendo el trabajo de Østergaard-Nielsen (2009: 20-21), la participación política de los migrantes va a depender de las formas de participación en la patria natal y de las estructuras políticas de oportunidad del país de residencia, en intersección con los regímenes de incorporación de los migrantes y las definiciones de las ciudadanías locales. Para esta autora, las prácticas políticas transnacionales de los migrantes tendrían como objetivo general la mejora de su situación, tanto en origen como en destino. Y si nos referimos a los proyectos de codesarrollo y a la participación de las asociaciones de migrantes en los mismos, podríamos pensar que estos proyectos constituyen una suerte de prácticas políticas de emigrantes orientadas a los gobiernos de sus países de origen para institucionalizar su estatus como migrantes o refugiados residentes en el exterior y aumentar sus derechos, solicitar esquemas de inversión, exención de impuestos, sistema de pensiones, etc. Del mismo modo, algunos de los miembros de las asociaciones pueden presentarse como candidatos a los congresos de los países en origen. Además, las actividades políticas de las asociaciones pueden orientarse a las llamadas políticas local-loca 5 , centradas en la mejora de la situación de las comunidades locales de origen a través de la participación de los migrantes en el desarrollo local, lo que puede implicar la participación electoral en elecciones municipales. Esta misma autora, en un texto posterior, centra su análisis en las prácticas de las administraciones y de la política local, y en cómo el codesarrollo ha devenido en una política de integración en los lugares de recepción, vinculando la ciudadanía local con las prácticas transnacionales de la migración. De hecho, destaca cómo el ámbito municipal y regional es el entorno político que fomenta y aboga específicamente por el impulso de los vínculos transnacionales. Las políticas de codesarrollo, desde la óptica de la integración de los migrantes, implican un proceso simultáneo de localización y transnacionalización de la ciudadanía migrante (Østergaard-Nielsen, 2011).

\subsection{Asociacionismo y estructuras de oportunidad}

Uno de los rasgos característicos de las asociaciones de migrantes en España, que destaca la literatura ${ }^{6}$ y declaran las propias asociaciones en sus discursos,

5. Traducción de las autoras, el término original en inglés es local-local politics (ØstergaardNielsen, 2009:22).

6. Por citar algunos textos de referencia, se pueden mencionar: Las asociaciones de inmigrantes en Madrid (2006), de González y Morales; Las asociaciones de inmigrantes: Un nuevo agente socio-político (2008), de Herranz; Informe sobre el asociacionismo marroqui y maliense en España: Inmigración y codesarrollo (2008), de López, o Las Asociaciones de Inmigrantes en España: Práctica clientelar y cooptación politica (2003), de Veredas. 
es su debilidad institucional y organizativa apoyada en causas diversas: los impedimentos para poder establecerse en un contexto nuevo, las dificultades para conseguir financiarse y profesionalizarse, la necesidad de compatibilizar y conciliar la labor asociativa con las jornadas laborales de sus integrantes, los problemas de representatividad y/o las tensiones entre sus miembros. Paralelamente a las dificultades derivadas de la propia organización y gestión, cada asociación se va especializando en un tipo de actividad, prioriza unas acciones u otras y representa a población diferente que, en muchas ocasiones, procede del mismo país, pero de regiones o localidades diversas, orígenes que pueden ser incompatibles para aunar esfuerzos y congregar lealtades en torno a las mismas causas. Además, como cualquier otro espacio de actividad, en este caso impulsado por la migración, también las asociaciones son entendidas como espacios que posibilitan una salida laboral y personal para algunos de sus miembros, un escenario que permite entender las dificultades del tejido asociativo para formalizarse y regularizarse, para ganar presencia pública en origen y en destino, así como para coordinarse entre ellas, pues compiten por sumar afiliados a sus organizaciones, por lograr subvenciones y poder de negociación en las plataformas donde están representadas.

Lo que vemos con la incorporación de las asociaciones al codesarrollo es cómo los proyectos permitieron canalizar la participación política transnacional de los migrantes. Los proyectos tienen implicaciones políticas para sus actores, tanto en España como en los contextos políticos nacionales y locales en origen. En este sentido, «un análisis comprehensivo del asociacionismo de inmigrantes ha de incluir una perspectiva transnacional con la que aprehender las redes y las prácticas que cruzan y redefinen las fronteras estato-nacionales» (Østergaard-Nielsen, 2003). Conviene no perder de vista que las organizaciones de migrantes que se han implicado en acciones de codesarrollo han estado a menudo insertas en redes transnacionales, autonómicas y locales, cada una con sus propias especificidades, que condicionan de modo interactivo las relaciones de las organizaciones de inmigrantes con otros actores de la sociedad civil y con los poderes públicos (Landolt, 2008). En el caso español, estudios comparativos de las organizaciones de inmigrantes en Barcelona, Madrid y Murcia (Morales et al., 2009; Morales y Jorba, 2010) han mostrado la diversidad de las estructuras de oportunidad política local y regional y su impacto en las organizaciones de inmigrantes (Toral, 2010).

La participación política asociativa va a depender de la estructura o de la ventana de oportunidad. González y Morales (2006) hablan de cómo el grado de integración cívico-política de los inmigrantes está condicionado por cuatro factores principales: (1) las características individuales de los propios inmigrantes; (2) las características sociodemográficas de sus respectivos grupos de origen (tamaño, posición en la estructura socioeconómica, etc.); (3) el tipo de asociaciones y de redes organizativas de los inmigrantes, y (4) la estructura de oportunidades políticas (legal, institucional y discursiva) que ofrece el contexto de recepción. En un texto posterior, Moraes y Cutillas (2015) incorporan la perspectiva transnacional al esquema y señalan que la apertura 
de oportunidades políticas a nivel local, nacional y transnacional ha ejercido un impacto importante en la intensidad y en las características de las actividades sociales y políticas transnacionales que ya llevaban a cabo los migrantes. Las políticas de vinculación de los estados de origen, tanto a partir de la promoción de la cooperación con la patria natal como de la organización de la diáspora con el objetivo de establecer interlocutores válidos y representativos de la comunidad de emigrantes, han ejercido una influencia importante en estas organizaciones (Moraes et al., 2009). En este sentido, las autoras apuntan además que han prevalecido las perspectivas sincrónicas frente a las diacrónicas, por lo que poco se sabe sobre las trayectorias de las asociaciones y los procesos de transformación y de cambio por los que han atravesado. En el caso que nos ocupa, el codesarrollo constituyó una ventana de oportunidad que los migrantes pudieron aprovechar con resultados diversos y alcances variados según los casos. Así, Lacomba (2016) habla del codesarrollo como de una «ventana de oportunidad política» en el impulso de las organizaciones y pone el foco en la pérdida de autonomía de estas y en los peligros de cooptación de la agenda asociativa por los intereses del Estado y de las administraciones locales y autonómicas. Pero, junto a esa constatación, no es menos cierto que las asociaciones han sabido aprovechar esa agenda política «desde arriba» para activar, legitimar e impulsar sus propios procesos «desde abajo»; desde grupos informales que trabajan al margen de las subvenciones y del resto de actores del ámbito de la cooperación española, pero también desde asociaciones y ONGD propias, que aprovecharon el nuevo espacio de la cooperación y los elementos específicos y distintivos del codesarrollo para ocupar un espacio de liderazgo, protagónico y diferencial, que les permitió introducir conceptos como los de ayuda mutua entre compatriotas, cooperativismo o trabajo horizontal con los lugares de origen (Sanmartín, 2011). Desde las asociaciones de migrantes se apeló al sentimiento de responsabilidad sobre el desarrollo de sus propios países y se abogó por superar la visión más paternalista de la cooperación, como una forma alternativa de plantear el desarrollo, incluyendo elementos del bienestar de la persona, «el buen vivir», la educación, la salud, el desarrollo local y el desarrollo de capacidades (Piras et al., 2013).

En esa misma línea, Moraes y Cutillas (2015) señalan: «si el contexto y los actores gubernamentales, políticos y sociales de origen y recepción han condicionado la organización, las acciones y las movilizaciones de las asociaciones de migrantes latinoamericanos, también se han visto influidos en diverso grado, alcance e intensidad por éstas». En su trabajo, las autoras muestran cómo el incorporar la dimensión transnacional al enfoque de las estructuras de oportunidad política y tener en cuenta las limitaciones estructurales permite conocer con mayor profundidad el impacto político del asociacionismo migrante. Las prácticas cívico-políticas de los migrantes y sus organizaciones son parte de un mecanismo continuo de retroalimentación a través del cual los migrantes influyen y son influidos por el ambiente político, institucional, nacional, local y transnacional (Østergaard-Nielsen, 2009). En este trabajo, el análisis del codesarrollo como ámbito de participación política transnacional de las aso- 
ciaciones de migrantes latinoamericanos nos permite entender la dimensión transnacional de las estructuras de oportunidad política del contexto español y cómo éste es usado por las asociaciones como sujetos políticos. Este enfoque es novedoso en los estudios sobre la acción colectiva de los migrantes, especialmente para la antropología, donde estas temáticas han recibido una atención marginal (Peró, 2009).

\section{Análisis de casos: la práctica del codesarrollo en la ciudad de Madrid}

El modelo español de migración y desarrollo sitúa como actor fundamental del proceso a las diásporas y a las asociaciones de migrantes, de forma que ambos conceptos aparecen unidos y usados de forma ambivalente. En España las actuaciones que detectamos en el ámbito asociativo y respecto a los ejemplos que trata la literatura estadounidense difieren en un aspecto que se revela fundamental: las asociaciones migrantes tienen una trayectoria marcada por el apoyo de actores nacionales para su creación y consolidación (ONGD, sindicatos, administraciones, etc.), y una de sus características es la debilidad de sus estructuras y la dependencia de las subvenciones para asegurar la continuidad de sus actividades. Por lo tanto, aquí radica una particularidad del contexto español: la manera que tienen los migrantes de organizarse en entidades, en su grado de dependencia o independencia respecto al diseño de estrategias propias de actuación y en el tipo de actividades que ponen en marcha ${ }^{7}$. En respuesta al marco en el que surgen y a la realidad a la que han de responder, se han especializado en la asistencia a los compatriotas, en la reivindicación de derechos y/o en la puesta en marcha de propuestas de carácter sociocultural, y han establecido relaciones directas con las administraciones públicas, con las que han de negociar para obtener subvenciones o representatividad en mesas y en foros de consulta y de diálogo. Por tanto, existe un interés por trabajar desde arriba con las asociaciones, por institucionalizarlas, y unos mecanismos que abren la puerta a relaciones clientelares y poco independientes de estas con respecto a aquellas (Veredas, 2003).

En relación con sus vínculos con el origen y con actuaciones de fomento del desarrollo, hemos identificado a dos situaciones dentro del tejido asociativo, cada una a un lado de un continuo en el que también se ubican situaciones intermedias:

7. La particularidad del caso español radica en el papel que han desempeñado determinadas organizaciones sociales como sindicatos y ONG en el apoyo a las organizaciones migrantes, al igual que el papel desempeñado por las administraciones públicas locales, quienes, a través de las convocatorias de codesarrollo, buscaban fortalecer institucionalmente a las asociaciones de migrantes recién constituidas. Este proceso es diferente de otros casos de asociaciones de migrantes, en especial del caso de las organizaciones de migrantes mexicanos en los EE. UU., en el que, tras décadas de migración continua, se han consolidado densas redes migratorias entre sus lugares de origen en México y de destino en Estados Unidos, afianzando sus formas organizativas, agrupándose en federaciones y confederaciones y ganando en formalización y visibilidad transnacional (Escala-Rabadán, 2014; Goldring, 2002). 
- La constitución de la asociación migrante como una ONG de desarrollo, que concurre a las subvenciones públicas para la realización de proyectos con el país de origen y que participa en proyectos de cooperación y codesarrollo junto a otros actores nacionales, es decir, aquellas que se insertan en las estructuras existentes para trabajar en cooperación.

- El caso de grupos informales o preasociaciones, con apenas estructuras y recursos, modalidad muy presente en España dada la debilidad de su organización institucional, el voluntarismo de sus miembros, la pluralidad de grupos y entidades y la llegada reciente, o relativamente reciente, de los colectivos (fundamentalmente si los comparamos con los colectivos migrantes residentes en los EE. UU.).

En un caso o en el otro, a pesar de tener un impacto en una escala reducida y de las dificultades y de las ambigüedades que mostraba su puesta en práctica, las actuaciones y las estrategias en el ámbito del codesarrollo permitieron a las asociaciones, como algo novedoso, consolidarse en el país receptor, participar en espacios con la Administración pública local y regional y avanzar en su institucionalización en los lugares de origen. Y pese al posible clientelismo y a la subalternidad de las asociaciones en los proyectos, para las asociaciones ese espacio resultó clave para activar proyectos propios, reforzar su presencia pública, ampliar contactos, etc. Las intrincadas relaciones de colaboración y competencia que en este terreno se generaron entre las asociaciones migrantes y las ONGD ejemplifican bien la conformación de esos espacios de oportunidad de liderazgo y subalternidad.

Tradicionalmente, en España han sido las ONGD las que han ocupado el espacio de la asistencia primaria a la población inmigrante en los lugares de llegada y las que han realizado proyectos de cooperación al desarrollo. Por tanto, cuando las administraciones impulsaron los proyectos de codesarrollo, las ONGD irrumpieron con fuerza en este campo, fundamentalmente aquellas que contaban con las dos ramas de actuación (de integración y de cooperación). Pero las convocatorias de codesarrollo incorporaron una novedad: los migrantes aparecen como puentes fundamentales entre las zonas por ellos conectadas, porque conocen los lugares de intervención y sus necesidades y tienen contactos, disponen de redes formales e informales que pueden facilitar la marcha de las acciones, la búsqueda de soluciones, etc., por lo que la participación de estos y sus asociaciones se establece como una de las claves del éxito de las iniciativas (Sanmartín, 2009).

Las asociaciones, por su parte, han recorrido su propia trayectoria, viviendo un cambio gradual de la especialización de sus actividades centradas fundamentalmente en el lugar de residencia hacia actividades que las conectan con el origen. Un cambio que tiene que ver con varios aspectos:

- El fortalecimiento de la propia estructura organizativa, el aumento de sus recursos y de su conocimiento del medio, que les permite afrontar actuaciones que trasciendan su entorno más inmediato y acceder a subvenciones para la realización de proyectos. 
- La constatación de que prestan cada vez menos servicios de tipo asistencial a medida que pasan los años y la población a la que atienden se va asentando en el país, por lo que la entidad se recicla y ofrece nuevos servicios y otro tipo de actuaciones.

- El propio interés de las administraciones públicas y el enfoque de sus subvenciones hacia actividades de cooperación con la participación de las asociaciones de migrantes, que fomenta la incursión, si es que no lo hacían ya, en actuaciones de desarrollo en los lugares de origen.

Es decir, los objetivos que asumen las asociaciones varían con el tiempo y suman nuevas acciones, $\mathrm{y}$ en dicho proceso hay un claro condicionamiento de la política oficial española, que incentiva mediante subvenciones unas actividades en detrimento de otras (Veredas, 2003).

En el caso concreto de los proyectos de codesarrollo, las administraciones públicas impulsaron "desde arriba» un trabajo de colaboración entre ONGD y asociaciones, lo que se tradujo en la presentación conjunta de proyectos y en la implementación de diversas actuaciones en el marco de los mismos (fortalecimiento de las redes asociativas en España y con los lugares de origen, etc.). La premisa es que no puede haber codesarrollo si no se trabaja en red, si no hay colaboración ni responsabilidades compartidas.

[se] fomentará [...] la constitución de agrupaciones y asociaciones, temporales o permanentes (es decir formas de colaboración articulada), entre ONG madrileñas, asociaciones de inmigrantes y ONG de origen que, por su especialización sectorial o geográfica, o por su complementariedad con otras, deseen voluntariamente aunar esfuerzos y presentarlos ya coordinados como una única solicitud, posibilitando la formulación de proyectos más integradores y de mayor impacto. (Decreto de 30 de marzo de 2007, Área de Gobierno de Empleo y Servicios a la Ciudadanía, por el que se aprueba la convocatoria pública de subvenciones para proyectos de codesarrollo)

Sin embargo, la práctica ha puesto de relieve que el codesarrollo así entendido también es un espacio de competencia: por concurrir a una convocatoria con fondos limitados; por tener un papel activo en la definición de objetivos, en las formulaciones y evaluaciones, $y$, en definitiva, por liderar los procesos que se ejecutan en nombre del codesarrollo, reclamando la legitimidad del tejido asociativo migrante para conectar los lugares de origen y de destino como algo propio, intrínseco a la naturaleza de sus actividades y de sus organizaciones.

Por tanto, en la relación entre ONGD y asociaciones migrantes se pusieron de manifiesto tensiones y desfases de intensidad y naturaleza diferentes. No solo resultaba complicado que ambas organizaciones trabajaran de manera horizontal entre ellas, pues no partían de situaciones equiparables - en cuanto a recursos, personal, disponibilidad, visibilidad, etc.- , sino que también tenían formas de actuar diferentes, debían responder ante prioridades y afiliados diversos y entendían la incidencia política y las necesidades de sus organizaciones de manera particular. 


\subsection{Los significados múltiples del codesarrollo en la arena transnacional}

El trabajo de campo realizado nos ha permitido analizar las diferentes vías de incorporación de las asociaciones a los proyectos y aportar una lectura diacrónica que arroje luz para entender qué significó para las asociaciones su incursión en el codesarrollo y cómo encajó esta actividad en sus trayectorias en términos de incidencia política transnacional.

Uno de los principales significados que el codesarrollo implicó para las asociaciones de migrantes es su rol como plataforma transnacional para obtener capital político, de tal forma que han constituido una vía de acceso al reconocimiento institucional como actores fundamentales a la hora de abordar la visibilidad y el acceso a derechos de la población migrante en los contextos de origen. De esta forma, el codesarrollo no se asoció solamente a la captación de recursos económicos, sino también a asegurar una doble presencia y un protagonismo político transnacional de ciertos grupos y asociaciones, al constituirse como un canal de participación que asegurase un cierto reconocimiento público. Una presencia que, en este caso, frente a la precariedad, se legitimó aglutinando a los migrantes en torno a ellas en nombre de una identidad compartida, que podía ser local, regional o nacional y/o social, y que permitió crear un sentimiento de pertenencia que identifica las causas por las que trabajar. Es el permanecer vinculados a la localidad de origen lo que proporciona el contexto social y espacial idóneo en el que tiene sentido realizar reivindicaciones y afirmaciones de estatus por parte de estos grupos (Goldring, 1998: 167). Además, tal como dicha autora señala, en estos proyectos existe un sentido de pertenencia en el que participar lleva implícita una noción de identidad que en la mayoría de los casos es más local que nacional.

Pero, además de asistir a este sentido de pertenencia, asistimos también a la emergencia de procesos identitarios globales, a la irrupción en la arena global de un «sujeto migrante». El ser migrante es lo que permite vincularse a los lugares de origen, a las reivindicaciones políticas por el papel de los migrantes allá y a la defensa de la realidad de los migrantes en los lugares de destino. El hecho de ser migrante legitima para intervenir, algo que vemos constantemente mencionado en el marco del codesarrollo: el migrante es una figura clave porque envía remesas y contribuye a la economía (familiar, local y, sumando aportaciones, nacional), porque lucha por la ampliación de derechos, por el voto desde el exterior, por implementar proyectos de desarrollo en origen:

Las asociaciones de migrantes valoran en el planteamiento del codesarrollo la posibilidad de involucrar el capital intelectual, social y cultural de los migrantes en el diseño óptimo para los proyectos. La justificación reside en la facilidad de gestionar los recursos y dialogar con personas que poseen intereses en común, mismas raíces culturales e implicación en los mismos objetivos como es el caso de los migrantes y sus zonas de origen. (Piras et al., 2013)

Y todo ello permite leer en otra clave el papel de la migración, su contribución al desarrollo, a la generación de cambios, a la lucha política y, por consi- 
guiente, le aporta argumentos para exigir derechos y poder de representación. Reclamar la existencia de una subjetividad migrante guarda relación con la emergencia actual de proyectos identitarios como el feminista, el medioambientalista o el globalista en la formación de movimientos transnacionales de base y su articulación con proyectos nacionales (Guarnizo y Smith, 1998: 7).

Una de las vías para profundizar esta subjetividad migrante es la participación a través de las asociaciones que, además, reivindican ser reconocidas como interlocutoras, actoras y agentes legítimos de desarrollo en la esfera transnacional:

Y creemos que el marco del codesarrollo es el espacio en el que se debe conceder protagonismo a las personas inmigrantes, a las organizaciones de inmigrantes, puesto que somos agentes transnacionales que generamos desarrollo aquí y allí y, partiendo de propuestas microlocales, quizás podamos llegar a articular unos trabajos y unos proyectos interesantes con las instituciones y con los gobiernos nacionales, de cada uno de los países. (Madrid, 2008, Representante Asociación Rumiñahui).

La preocupación por articular las sugerencias de los migrantes con la política nacional de origen o con la política local del contexto receptor dependió de las distintas propuestas políticas que iban realizando los países de origen. Muchos de los planteamientos de las asociaciones se quedaban en posición de espera hasta que cambiaban las circunstancias políticas de aquellos. Por ejemplo: la asociación Rumiñahui llevaba planteando proyectos para atender a la población ecuatoriana que salía de Quito y llegaba a Madrid desde el año 2002, pero hasta que no se produjo el cambio en la política migratoria del Ecuador y el gobierno de Correa empezó a desarrollar una clara acción transnacional estatal con sus migrantes, las iniciativas de esta asociación no fueron incorporadas a las discusiones de la sociedad civil en la Asamblea Constituyente del Ecuador de 2008. La relevancia de esta asociación se vio reconocida por el hecho de que su presidenta, Dora Aguirre, fue elegida asambleísta por Europa, Asia y Oceanía en dos ocasiones, en los periodos 2009-2013 y 2013-2017. Por su parte, la asociación Rumiñahui ha mantenido su actividad tanto en Ecuador como en España. En todo este proceso, los proyectos de codesarrollo que esta asociación ha estado impulsando desde 2002 han desempeñado un papel decisivo para asegurar su presencia en ambos países (Cortés, 2011; Cortés, 2018).

Además de reconocimiento externo, se esgrime la potencialidad de los propios migrantes como actores políticos en espacios transnacionales:

Dentro de que las cooperaciones al desarrollo y al codesarrollo constituyen medidas marginales que pueden contribuir al desarrollo, digamos que no se está pensando solo en actividades micro, sino también en cómo ese sujeto social, que tiene que ser un actor político, pues puede incidir en transformar esa realidad, que tiene una interdependencia a nivel global aquí y allá y cómo aprovecha ese espacio de codeterminación que se crea por las migraciones entre origen y destino para buscar políticas compartidas donde también su voz, su 
interés, sobre todo, esté recogido [...] Por todo eso, el descubrimiento hace que se empiece a elaborar un cierto discurso político de la inmigración, pero tiene esa singularidad, y es recoger el interés migrante, entender al migrante como el actor que no pide solo para él mismo, sino que, siendo el sector más frágil de la sociedad receptora, plantea soluciones de tipo integral para arreglar determinados problemas. (Madrid, 2008, Representante Asociación AESCO)

Se reivindica, pues, el ser parte activa en la consecución de cambios políticos y sociales, en la posibilidad de incidir en los contextos de origen y recepción y en el campo transnacional. Pero no se trata de reivindicar un espacio exclusivo, sino en colaboración con otros actores, posiblemente asumiendo la posición periférica de las propias asociaciones.

El codesarrollo creo que debe empezar porque los inmigrantes influyan cada vez en el país de origen para que haya cambios políticos, para que se democraticen, para llevar a cabo uno de los objetivos, uno de los planes incluso de Naciones Unidas de la buena gobernanza, etc. (Madrid, 2008, Portavoz REDCO)

Uno de los objetivos que tenemos es un objetivo de inclusión. El inmigrante es un inmigrante presente, no es un inmigrante ausente, es un inmigrante de afuera pero presente. Creo que esa conceptualización es una cosa que tiene trascendencia social, trascendencia económica, trascendencia política, lo que es un proyecto integral por la capacidad de gente a la que agrupa. (Madrid, 2008, Representante Asociación VOMADE)

Uno de los aspectos más importantes para las asociaciones era aprovechar los proyectos de codesarrollo para reforzar redes y estructuras organizativas, para revitalizar las asociaciones. Por tanto, se trataba de dirigir sus acciones a los contextos de origen, pero, al mismo tiempo, proyectar sus efectos en Madrid tratando de revertir la posición subalterna de las entidades. Este es uno de los riesgos de la apertura de ventanas de oportunidad: hacer que las nuevas categorías (en este caso, el codesarrollo) sirvan para solucionar todos los problemas que se encuentran en la agenda política:

Para nosotros, el codesarrollo pretende dar respuesta a dos cuestiones clave. Una es el fortalecimiento del movimiento asociativo en España y dos el desarrollo en los países de origen, en zonas y en sectores clave, en ciudades de mayor flujo migratorio que permitan la creación de redes internacionales de apoyo. (Madrid, 2008, Representante Asociación ACULCO)

Estas formas de conceptualizar el codesarrollo y el lugar de las asociaciones en él no puede entenderse sin atender a las propias trayectorias de las asociaciones que se han implicado en actuaciones de este tipo. Algunos casos permiten ejemplificar estas trayectorias de manera sucinta: organizaciones que han ido adaptando su actividad, transnacionalizando su incidencia a medida que se iban asentando en España; asociaciones que se conceptualizaban desde sus inicios en los años noventa en un espacio transnacional de participación a partir de su 
vinculación comprometida con una serie de transformaciones democráticas que estaban teniendo lugar en América Latina, y otras que respondían al impulso de las subvenciones públicas para sumar a su trabajo la actividad que las conectaba con el origen. En este sentido, muchos de los proyectos de codesarrollo permitían incidir en las diferentes escalas geopolíticas que atravesaban y que atraviesan las vidas de los migrantes:

[...] nosotros entendemos el codesarrollo en varias facetas, una faceta que es a nivel de los estados, otra a nivel de las regiones, otra a nivel de los municipios y otra a nivel de las personas, y en ese sentido nosotros vimos que, como asociación, el hacer la asociación allí era un proyecto también de codesarrollo, puesto que se financió también por los inmigrantes de acá. (Madrid, 2008, Representación Asociación VOMADE)

Todo lo anterior muestra una valoración amplia, plural y de considerable expectativa hacia el codesarrollo por parte de las asociaciones y de sus miembros destacados. Sin embargo, dichas consideraciones contrastan con el escaso desarrollo que se logró y por la reducida dimensión conseguida, si nos atenemos a criterios de número y escala de los proyectos, monto económico o impactos en origen. ¿Por qué tanto interés, entonces? La explicación podría encontrarse en que las asociaciones están interesadas en participar en procesos que les permitan trascender el marco tradicional de intervención, cambiar las condiciones y las relaciones presentes en el desarrollo a partir de una fórmula nueva que es el codesarrollo. Por muy reducida que esta haya sido, significa abrir una brecha, una veta en el ámbito de la participación política de los migrantes, y profundizar la ciudadanía como una realidad negada, tanto en España y en Madrid como en los contextos de origen, donde los migrantes han luchado contra la invisibilidad política y social. En unos casos eran formas de lucha; en otros, de escape, y en otros, de resistencia a las estructuras sociales, raciales y de cambio en origen y en destino (Basch et al., 1994: 46). En definitiva, estos grupos se están abriendo a sí mismos nuevas posibilidades y dimensiones para la ciudadanía, al enmarcar su lucha en procesos que no se vinculan de forma directa con el territorio. Precisamente las organizaciones de migrantes se configuran como espacios mediadores de ciudadanía que median entre las personas y la comunidad política (nación, región, localidad, barrio) (Goldring, 2005).

\section{Administraciones locales, promoción del codesarrollo y asociaciones de migrantes}

Tal y como habíamos señalado con anterioridad, las prácticas políticas transnacionales de las asociaciones de migrantes pueden constituir una respuesta a las políticas impulsadas desde los contextos receptores. En esta línea, las primeras propuestas de codesarrollo en Madrid (a finales de la década de 1990) desde las administraciones generaron más bien dudas entre los migrantes. Las asociaciones de migrantes fueron entonces críticas con el modelo que trataba de introducirse: 
Estas organizaciones desconfiaban de un concepto que podía ser enmarcado dentro de las políticas de retorno voluntario impulsadas por la Unión Europea. Por lo tanto, esta primera época se caracterizó por la resistencia al impulso, "desde arriba», de una visión determinada del codesarrollo más próximo a las políticas de control de flujos migratorios que a la promoción del desarrollo en los lugares de origen de la migración. (Cortés y Sanmartín, 2008: 69)

Pero debido a que la Administración consistorial madrileña estaba interesada en ser una de las primeras administraciones locales en impulsar una convocatoria propia de codesarrollo, compitiendo con otros municipios españoles, invitó especialmente a varias ONGD y a asociaciones de migrantes a concurrir a las convocatorias. La perspectiva municipal manejó un discurso inclusivo, presentando el territorio y sus políticas como un espacio de participación ciudadana en el ámbito de los planes de integración que se habían diseñado y que se estaban impulsando por el Ayuntamiento de Madrid, manteniendo el principio de coherencia con la política de integración estatal. En este marco, el codesarrollo se entendía como una dimensión de la política pública donde la participación migrante en su diseño e implementación resultaba clave, como un conjunto de acciones impulsadas entre Administración y organizaciones sociales, como un instrumento para impulsar la mejora de la convivencia.

Esto hizo que las asociaciones dejaran de lado temporalmente sus recelos y participaran en las convocatorias. Como ya hemos comentado anteriormente, las subvenciones de codesarrollo fueron adjudicadas inicialmente a las ONGD madrileñas, pero eso fue cambiando gradualmente, puesto que aumentó progresivamente el número de proyectos y la presencia de organizaciones migrantes entre ellos. En 2004, de un total de seis proyectos aprobados, no hubo ni una sola entidad migrante entre las beneficiarias. En cambio, en 2008, de los once aprobados, hubo cuatro organizaciones migrantes con subvención directa a sus proyectos. Como resultado, las asociaciones más veteranas que participaron en estas y en otras convocatorias desarrollaron lazos muy estrechos con las administraciones públicas en todos los niveles, lo que dio lugar a un modelo de relación entre la Administración y las asociaciones de arriba a abajo (LópezSala y Cebolla, 2015).

Vemos, por tanto, que las asociaciones se interesaron por impulsar proyectos de codesarrollo desde sus organizaciones y por forjar una relación de confianza y cercanía con la Administración local, sobre todo con el objetivo de lograr que el Ayuntamiento de Madrid los viera como actores a la misma altura que las ONGD. Esta cuestión era de enorme importancia, porque implicaba poder participar en las convocatorias municipales de codesarrollo y competir por la obtención de subvenciones públicas en las mismas condiciones que las ONGD. En este sentido, las asociaciones han tenido que luchar por su reconocimiento frente a aquellas y a la Administración local financiadora de las convocatorias de proyectos, que desconfiaba de la capacidad de las asociaciones para recibir fondos y gestionar los recursos públicos asignados a los proyectos: 
[...] el Ayuntamiento ha tenido una política muy acertada y muy eficaz de cara a proyectos muy significativos en el mundo de la migración y el mundo del codesarrollo y del desarrollo, a pesar de que nosotros prácticamente solo hemos participado en un proyecto, porque ese es el otro problema que hay acá en España: las administraciones siempre ven a las asociaciones de emigrantes con cierta desconfianza, como incapaces de administrar, incapaces de gestionar, incapaces de llevar a cabo algunas cosas de cara a sus comunidades. (Madrid, 2008, Representante Asociación VOMADE)

En los proyectos de codesarrollo, una de las líneas de trabajo más potenciadas desde la convocatoria municipal madrileña consistió en el fortalecimiento de las organizaciones de migrantes, debido a la debilidad estructural en la que estas asociaciones se han encontrado. De ahí que algunos de los primeros proyectos trabajaran específicamente la formación de redes asociativas o de comités de representantes de diversas entidades en Madrid, con el objetivo de reforzar además los puentes de dichas organizaciones con sus localidades de origen.

Sin embargo, hay un aspecto que es preciso matizar: las asociaciones de migrantes eran reconocidas en España como tales, lo que las situaba en una posición diferente respecto a sus contextos de origen. Mientras que, en España, y en nuestro caso en Madrid, tenían reconocido un espacio en disputa con otros actores que las situaba en una posición subalterna en la sociedad civil, en origen, las acciones se dirigían sobre todo a visibilizar la mera existencia de una problemática invisibilizada en las agendas mediáticas y políticas: la necesidad de atender a la población que se marchaba sin derechos, sin seguridad, sin atención ni interés por parte de sus gobiernos.

Previo a todo, y como marco de fondo, se encuentra la relación entre el Estado y las ONG, pues es desde ahí desde donde se realiza la relación con las asociaciones. Los proyectos de codesarrollo surgieron en un contexto en el que ya había una historia previa y una manera de entender las relaciones entre las administraciones (central, autonómica y local) y el mundo de las asociaciones de migrantes. Durante el largo periodo de realización del trabajo de campo, fueron varios los llamamientos que hacían ciertos representantes de las asociaciones al peligro de cooptación política de las asociaciones por partidos políticos y administraciones públicas, con la consiguiente configuración de relaciones de clientelismo:

[...] ciertas administraciones quieren su propia clientela y además no quieren que los inmigrantes se organicen de una forma muy sólida, porque entonces hay que dialogar con ellos, y además de una forma también seria y sólida. Lo que quieren es que sean, así, satélites dentro de unas iniciativas de otras organizaciones que más bien pueden controlarlas. (Madrid, 2008, Portavoz REDCO)

En algunos casos, precisamente los proyectos de codesarrollo fueron entendidos como espacios al margen de estas dinámicas, como la oportunidad para crearse un lugar propio de incidencia y de reconocimiento frente a las admi- 
nistraciones públicas madrileñas (el Ayuntamiento de Madrid y la Comunidad de Madrid, que representaban distintos modelos de gestión de la migración), y con presencia en los contextos de origen. Las organizaciones decidieron no desechar oportunidades y ganar peso en el contexto público español, en el espacio de negociación y participación creado, y aprovechar la coyuntura para ocupar un lugar que hasta entonces no tenían: las administraciones las reconocían como actores estratégicos para los proyectos y las ONG empezaron a contar con ellas para poder acceder a las subvenciones.

Sin embargo, transcurrido un cierto tiempo de política migratoria municipal, se empezaron a identificar ciertas señales de agotamiento del modelo, de los liderazgos asociativos y del alcance de los logros de las políticas locales. Las asociaciones habían tenido que afrontar procesos de trasvase político de ciertos líderes que ocuparon puestos en partidos o que se habían vinculado a partidos, tanto en España como en los contextos de origen, lo que generaba críticas en el mundo asociativo por la falta de independencia, por la poca transparencia en la finalidad de sus organizaciones:

Hemos pertenecido en estos años a varias redes en España y Colombia, pero nos ha decepcionado la ineficacia de las mismas o la partidización política, lo que nos ha hecho retirarnos. (Madrid, 2008, Representante Asociación ACULCO)

Es decir, la concurrencia y la participación en los proyectos pusieron de relieve las tensiones por ocupar un espacio político de representación, por acceder a subvenciones con recursos escasos, y evidenciaron una realidad que desde las propias asociaciones consideraron «susceptible» de generar prácticas clientelares. Sin embargo, a pesar de ese posible clientelismo y de la subalternidad, para las asociaciones ese espacio siguió siendo clave para reforzar su presencia, sus contactos, sus proyectos propios, etc.

Supuso un antes y un después en la Asociación, porque nos dimos cuenta de que estábamos trabajando cojos y después porque nos vimos capaces de trabajar en esta área con toda la información, así como la necesidad del inmigrante aquí y las posibilidades que tenemos de actuar allí. (Madrid, 2008, Representante Asociación ACOBE)

\section{Conclusiones}

Los proyectos de codesarrollo han sido entendidos por las asociaciones de migrantes como estructuras de oportunidad que les ayuden a sortear las limitaciones para ejercer la ciudadanía, tanto en Madrid como en origen. Las vidas cotidianas de los migrantes se caracterizan por relaciones transnacionales que pueden implicar contradicciones y tensiones entre los diferentes contextos. Las asociaciones han dirigido sus agendas de manera transnacional aprovechando los resquicios que se iban abriendo para participar allí donde sus vidas tenían lugar. Mientras que, en origen, la lucha se dirigía a reclamar su papel 
como «sujetos migrantes presentes» con derechos y a revertir la exclusión como "ciudadanos migrantes ausentes», recordando a través de la participación en proyectos de codesarrollo, entre otras actividades, que siguen estando presentes, que siguen perteneciendo a un espacio que invisibiliza la exclusión y las violaciones de los derechos humanos a las que se ven sometidos ellos y sus familias, en Madrid, las acciones se dirigían a conseguir un tipo específico de reconocimiento y un espacio de participación política en la definición de la agenda del desarrollo.

El trabajo de campo ha mostrado cómo las trayectorias y las características de las tramas asociativas de migrantes latinoamericanos condicionaron el impulso y la puesta en práctica del codesarrollo en la ciudad de Madrid. Éste consistía en una iniciativa que actuaba como una línea de trabajo que encajaba en sus acciones y, fundamentalmente, como una actividad que trascendía los límites territoriales de la acción asociativa, lo que daba lugar a itinerarios diversos marcados siempre por las posibilidades de trabajo desde las estructuras con las que contaban las asociaciones migrantes (en cuanto a personal, recursos, experiencia previa, redes, etc.).

Pero, además, la manera en que el codesarrollo se impulsó desde Madrid impactó a su vez en el discurso, la orientación y el proceso de transnacionalización de las asociaciones de migrantes. Las políticas públicas y la influencia de la Administración local condicionaron desde arriba las maneras reconocidas de interlocución. No en vano fueron ciertas organizaciones las que obtuvieron apoyo financiero, y fueron determinadas entidades las que se mostraron más útiles a la hora de concurrir a las convocatorias. Hemos visto cómo fueron fundamentalmente las asociaciones latinoamericanas las que participaron en los proyectos desde Madrid, y cómo la competencia entre las ONGD y las asociaciones animó a estas últimas a impulsar la cooperación como actividad clave y a esgrimir mayor legitimidad en este terreno, aludiendo a la naturaleza transnacional del ser migrante y, por tanto, de sus entidades como legítimas representantes de los territorios y de las gentes por ellos conectadas. Un campo de competencia que condujo, así mismo, a la búsqueda de estrategias de inclusión alternativas, como la presentación de propuestas conjuntas entre entidades migrantes a partir de la creación de redes de asociaciones que adquirieran fortaleza frente a las ONGD, los actores más reconocidos en el ámbito de la cooperación.

Los migrantes han luchado por ser ciudadanos de diferente modo, en diferentes escalas y espacios políticos. Al hacerlo, han realizado distintas actividades y han explorado vías también distintas, y el codesarrollo ha sido una de ellas. Esto ha contribuido a reforzar el carácter transnacional de las asociaciones, porque el codesarrollo permitió abrir una oportunidad para trabajar la incidencia política tanto en origen como en Madrid, puesto que situaba su agencia en una dimensión transnacional de la ciudadanía, con lo que se superó la dimensión estatal de la misma. El codesarrollo permitió reactivar reivindicaciones antiguas y proponer otras nuevas, así como actuar ocupando un espacio en un marco transnacional de incidencia. Como desde la precariedad y la falta de recono- 
cimiento de derechos no es posible aprovechar las dinámicas positivas de la migración en el desarrollo, se vuelven a poner sobre la mesa las deficiencias del sistema político, los problemas que afrontan los migrantes, su invisibilidad política, económica y social, y se suma a la reivindicación de sus competencias la legitimidad para vincularse formalmente a los contextos de origen a través de actividades de cooperación para el desarrollo.

\section{Referencias bibliográficas}

Basch, Linda; Glick SChiller, Nina y Szanton Blanc, Cristina (1994). Nations Unbound: Transnational Projects, Postcolonial Predicaments, and the Deterritorialized Nation-State. Nueva York: Gordon and Breach. <https://doi.org/10.4324/9780203347003>.

Cordero-GuzMÁn, Héctor R. (2005). «Community-Based Organizations and Migration in New York City». Journal of Ethnic and Migration Studies, 31(5), septiembre, 889-909. <https://doi.org/10.1080/13691830500177743>.

CORTÉS, Almudena (2011). Estados, Cooperación para el Desarrollo y Migraciones: El caso del Codesarrollo entre Ecuador y España. Madrid: editorial Entimema.

CORTÉS, Almudena (2018). «Gobernanza Local y Codesarrollo: un estudio de caso entre Ecuador y España». En: YéPEZ, Isabel; LAfLeUr, Jean-Michel y HerrerA, Gioconda (eds.). Migraciones internacionales, Estado, crisis y desarrollo en Ecuador y Bolivia. Quito: FLACSO/Centre d'Etudes pour le Développement (CED - Université Catholique de Louvain), 83-109.

CORTÉs, Almudena; MONCÓ, Beatriz y BeTRISEY, Débora (2015). Movilidad transnacional de jóvenes españoles y latinoamericanos: una comparación en contextos de crisis, Madrid: Centro Reina Sofía sobre Adolescencia y Juventud, FAD.

CORTÉS, Almudena y SANMARTín, Anna (2007). «Política transnacional: Asociaciones migrantes y codesarrollo». El Viejo Topo, 239 (diciembre).

- (2009). «Las prácticas transnacionales de los/las migrantes vinculadas al desarrollo: Un estudio a partir del contexto español». Revista del Ministerio de Trabajo e Inmigración: Migraciones Internacionales, 80, 191-209.

CORTÉS, Almudena y TORRES, Alicia (2009) (coords.). Codesarrollo en los Andes: Contextos y actores para una acción transnacional. Quito: FLACSO-Ecuador, IMEDESUAM y Cooperación Ciudad de Madrid.

Doré, Carlos; ItZigsohn, José; Hernández, Esther y VÁzQuez, Obed (2003). "Cartografía del transnacionalismo dominicano: amplias y estrechas vinculaciones transnacionales». En: PORTES, Alejandro; GuARnizO, Luis Eduardo y LANDOLT, Patricia (eds.). La globalización desde abajo: Transnacionalismo inmigrante y desarrollo. México DF: Flacso México.

Escala-RABADÁN, Luis (2014). «Asociaciones de inmigrantes mexicanos en Estados Unidos: Logros y desafíos en tiempos recientes». Desacatos, 46 (septiembre-diciembre), 52-69. <https://doi.org/10.29340/46.1356>.

FernándeZ, Mercedes; Giménez, Carlos y Puerto, Luis Miguel (eds.) (2008). La construcción del codesarrollo. Madrid: La Catarata.

Giménez, Carlos; Martínez, Julio; Fernández, Mercedes y Cortés, Almudena (2006). El codesarrollo en España: Protagonistas, discursos y experiencias. Madrid: La Catarata. 
GOLDRING, Luin (1998). "The power of status in transnational social fields». En: Smith, Michael Peter y GuARnizo, Luis Eduardo (eds.) Transnationalism from bellow. New Brunswick: Transaction Publishers.

- (2002). "The Mexican State and transmigrant organization: Negotiating the boundaries of membership and participation». Latin American Research Review, 37(3), 55-99.

<http://www.jstor.org/stable/1512514>.

- (2005). «Multi-layered multi-local citizenship practice: Chileans in Canada». Invited presentation for the Conference on «Migration: Transnational Reconfiguration and Population Flows», Universidad Iberoamericana de Puebla. Puebla, México: October 19-21.

GonZÁlez, Amparo y Morales, Laura (2006). «Las asociaciones de inmigrantes en Madrid: Una nota de investigación sobre su grado de integración política». Revista Española del Tercer Sector, 4, 129-173.

Group De Recherche et De Réalisation Pour le Développemenet RuralGRDR (2005). La Monographie: un outil d'animation et de la concertation. Dijon (Francia).

GuARNIZO, Luis Eduardo; SÁNCHEZ, Arturo Ignacio y ROACH, Elizabeth (2003). «Desconfianza, solidaridad fragmentada y migración transnacional: Los colombianos en la ciudad de Nueva York y Los Ángeles». En: PORTES, Alejandro; GuARnizo, Luis Eduardo y LANDOLT, Patricia (eds.). La globalización desde abajo: Transnacionalismo inmigrante y desarrollo. México DF: Flacso México.

GuarnizO, Luis Eduardo y SMITH, Michael Peter (1998). Transnationalism from Below. New Brunswick: Transactions Publishers, vol. 6. <https://doi.org/10.4324/9781351301244>.

HERRANZ, Inmaculada (2008). «Las asociaciones de inmigrantes: Un nuevo agente socio-político». En: Pérez DíAz, Víctor (coord.) (2008). Modernidad, crisis y globalización: Problemas de política y cultura. Valencia. Fundación Cajamar. Colección Mediterráneo Económico, 14.

LACOMBA, Joan (coord.) (2015). Diásporas y codesarrollo desde España: Un estudio sobre el papel de las asociaciones de inmigrantes en el desarrollo de los paises de origen. Granada: Comares.

- (2016). "Asociaciones de inmigrantes en la encrucijada: Acción transnacional y riesgos de cooptación». REMHU, XXIV (47), 27-44. <https://doi.org/10.1590/1980-85852503880004703>.

LANDOlT, Patricia; AUTLER, Lilian y BAIRES, Sonia (2003). «Del hermano lejano al hermano mayor: La dialéctica del transnacionalismo salvadoreño». En: PORTES, Alejandro; GuARnizO, Luis Eduardo y LANDOlT, Patricia (eds.). La globalización desde abajo: Transnacionalismo inmigrante y desarrollo. México DF: Flacso México.

LÓPEZ, Bernabé (dir.) (2008). «Informe sobre el asociacionismo marroquí y maliense en España: Inmigración y codesarrollo». Madrid: Taller de Estudios Internacionales Mediterráneos, Universidad Autónoma de Madrid, MPDL y TEIM.

LÓpez-SalA, Ana y Cebolla, Héctor (2015). «Transnational Latin American Immigrant Associations in Spain during the Economic Recession: A top-down model of integration and transnationalism at stake?». En: AYSA-LASTRA, María y CACHÓN, Lorenzo (eds.). Comparative Perspectives on the Great Recession and Latin American Immigrants. Springer International Publishing. <https://doi.org/10.1007/978-3-319-14797-0_9>. 
Mas Giralt, Rosa (2017). «Onward Migration as a Coping Strategy? Latin Americans Moving from Spain to the UK Post-2008». Popul. Space Place, 23: e2017. $<$ https://doi.org/10.1002/psp.2017>.

Moraes, Natalia; BermúdeZ, Anastasia; Escrivá, Ángeles y Padilla, Beatriz (2009). «Estrategias de vinculación de los Estados latinoamericanos con sus diásporas: un análisis de las iniciativas desarrolladas por Colombia, Perú, Brasil y Uruguay». En: Escrivá, Ángeles; Bermúdez, Anastasia y Moraes, Natalia (eds.). Migración y participación política. Córdoba: CSIC.

Moraes, Natalia y Cutillas, Isabel (2015). «Asociaciones de migrantes en España en perspectiva local-transnacional: Luchas, procesos de cambio y nuevos espacios de participación en tiempos de crisis». En: GARCía CASTAÑo, Francisco Javier; Megías, Adelaida y Ortega, J. (eds.). Actas del VIII Congreso sobre Migraciones Internacionales en España (Granada, 16-18 de septiembre de 2015), S24/10 S24/22). Granada: Instituto de Migraciones.

MorAles, Laura; GONZÁlEZ Amparo y JORBA Laia (2009). «Políticas de incorporación y asociacionismo de la población de origen inmigrante a nivel local». En: ZAPATA, Ricardo (ed.) Inmigración en España: claroscuros de las políticas y gobernabilidad. Barcelona: Ariel.

MORALES, Laura y JORBA, Laia (2010). "The transnational links and practices of migrants' organisations in Spain». En: BAUBÖCK, Rainer y FAIST Thomas (eds.) Diaspora and Transnationalism: Concepts, Theories and Methods. Amsterdam: Amsterdam University Press. <https://doi.org/10.5117/9789089642387>.

Østergaard-Nielsen, Eva (2003). «The Politics of Migrants' Transnational Political Practices». International Migration Review, 37, 760-786. <https://doi:10.1111/j.1747-7379.2003.tb00157.x>.

- (2009). «La política a través de las fronteras: Reflexiones sobre la dimensión transnacional de la participación política de los migrantes». En: ESCRIVÁ, Ángeles; BERMúDEZ, Anastasia y MORAES, Natalia (eds.). Migración y participación política. Córdoba: CSIC.

- (2011). «Codevelopment and citizenship: The nexus between policies on local migrant incorporation and migrant transnational practices in Spain». Ethnic and Racial Studies, 34(1), 20-39. <https://doi.org/10.1080/01419871003777791>.

PERÒ, Davide (2009). «Las movilizaciones políticas de los latinoamericanos en Londres». En: Escrivá, Ángeles; BermúdeZ, Anastasia y MoraEs, Natalia (eds.). Migración y participación política. Córdoba: CSIC.

Piras, Gioia; Cazarín, Rafael; Rennau, Anna; Bianchi, Gisela y Blanco, Cristina (2013). «El asociacionismo de la población andina en Madrid y País Vasco: Voces sobre el nexo migración y desarrollo». Memoria del VII Congreso sobre Migraciones Internacionales en España: Movilidad Humana y Diversidad Social. Bilbao: UPV/ EHU, 4379E3395.

Ramos, Cristina (2017). «Onward migration from Spain to London in times of crisis: the importance of life-course junctures in secondary migrations». Journal of Ethnic and Migration Studies, <https://doi.org/10.1080/1369183X.2017.1368372>.

SAnMarTín, Anna (2009). "Los actores del codesarrollo: El caso español». En: CorTÉS, Almudena y TORRES, Alicia (coords.). Codesarrollo en los Andes: Contextos y actores para una acción transnacional. Quito: FLACSO-Ecuador, IMEDES-UAM y Cooperación Ciudad de Madrid. 
- (2010). El codesarrollo en España: Un análisis de la implicación de los migrantes. Madrid: Instituto Universitario Ortega y Gasset (UCM). Tesis doctoral.

- (2011). "Las asociaciones de migrantes en las actuaciones de codesarrollo: Un estudio desde la ciudad de Madrid». Revista Migraciones, 30, 71-99.

SMITH, Robert C. (1998). «Transnational Localities: Community, Technology and the Politics of Membership within the context of Mexico and U.S. Migration». En: Guarnizo, Luis Eduardo y Smith, Michael Peter. Transnationalism from Below. New Brunswick: Transactions Publishers, 6.

Sørensen, Ninna; Van Hear, Nicholas y Engberg-Pedersen, Peter (2002). «The migration-Development Nexus: Evidence and Policy Options». Copenhague: Centre for Development Research.

TORAL, Guillermo (2010). «Las asociaciones de inmigrantes como sociedad civil: Un análisis tridimensional». Revista Española de Investigaciones Sociológicas, 132, 105-130.

VEREDAS, Sonia (2003). «Las asociaciones de inmigrantes en España: Práctica clientelar y cooptación política». Revista Internacional de Sociología, 36 (septiembrediciembre), 207-225.

$<$ https://doi.org/10.3989/ris.2003.i36.320>. 
